\title{
Tobacco use cessation efforts among private dental practitioners of Delhi, India
}

\author{
Abhishek Mehta ${ }^{1}$, Gurkiran Kaur ${ }^{2}$, Rishabh Popli ${ }^{3}$, Suchi Khurana ${ }^{4}$ \\ ${ }^{1}$ Department of Public Health Dentistry, Faculty of Dentistry, Jamia Millia Islamia, New Delhi, India. \\ ${ }^{2}$ Department of Oral Pathology and Microbiology, PDM Dental College and Research Institute, PDM University, Bahadurgarh, Haryana, India. \\ ${ }^{3}$ PDM Dental College and Research Institute, PDM University, Bahadurgarh, Haryana, India. \\ ${ }^{4}$ Department of Public Health Dentistry, PDM Dental College and Research Institute, PDM University, Bahadurgarh, Haryana, India
}

\section{Abstract}

Introduction: Tobacco use remains the single largest cause of premature death around the world. Motivating tobacco users through behavioral counseling is the mainstay for achieving tobacco abstinence. Research evidence suggests a larger role of dental professionals in motivating tobacco users to quit. The efforts of private dental practitioners in providing Tobacco Cessation Interventions (TCI) in their clinics need to be measured and acknowledged.

Methods: A cross-sectional survey based on self-administered questionnaire with private dental practitioners was carried out in the state of Delhi, India. The main objectives of the survey were to assess the current practices and the barriers experienced in providing TCl by the participating dentists. Statistical analysis was conducted to find out the association between independent variables and the responses to questions on tobacco cessation.

Results: The mean age and years of practice of 297 participating dentists was 37.2 (SD 9.8) and 11.9 (SD 9.5) years respectively. Most of them were graduate $(\mathrm{N}=204,68.7 \%)$. Only $17.2 \%(\mathrm{~N}=51)$ of the participating dentists had undergone any training in providing $\mathrm{TCl}$. Most of the dentists felt that the lack of proper training $(\mathrm{N}=146,49.2 \%)$ and resistance by patients $(\mathrm{N}=185,62.5 \%)$ are the main barriers in providing $\mathrm{TCl}$. Younger dentists ( $<35$ years) performed significantly better than older dentists in many parameters pertaining to attitude and practices of $\mathrm{TCl}$ in their clinics.

Conclusion: This is a pioneer survey conducted on the issue of $\mathrm{TCl}$ provided by private dental practitioners of Delhi. The study results show that around $2 / 3$ rds of the participating private dental practitioners were providing $\mathrm{TCl}$ to their patients but there are certain barriers for its proper implementation. Therefore, there is an urgent need to remove these selfreported barriers and build self-confidence among the dentists for instituting effective $\mathrm{TCl}$ in their clinics.
Key words: tobacco use cessation, dentists, questionnaire, nicotine replacement, India.

Citation: Mehta A, et al. (2020) Tobacco use cessation efforts among private dental practitioners of Delhi. Dentistry 3000. 1:a001 doi:10.5195/d3000.2020.99

Received: April 4, 2020

Accepted: May 14, 2020

Published: July 23, 2020

Copyright: (C2020 Mehta A, et al. This is an open access article licensed under a Creative Commons Attribution Work 4.0 United States License.

Email: amehta@jmi.ac.in

\section{Introduction}

Consuming tobacco increases the risk of several oral and general health problems such as cancer of oral, lung and pharyngeal region, cardiovascular problems and periodontal diseases [1]. It is estimated that by the year 2030, tobacco will be the leading cause of mortality in human population worldwide [2]. India is home to the second highest tobacco consumers in the world, with 267 million active tobacco users and more than one million tobacco related deaths occurring each year [3]. These numbers suggest we are in the second stage of tobacco epidemic [4].

A person can quit the habit of tobacco consumption with self-motivation and professional help.
Tobacco cessation programmes are gaining acceptance worldwide as they are found to be an effective preventive measure $[5,6]$. Tobacco cessation interventions ( $\mathrm{TCl}$ ) provided by physicians and dental care professionals have shown improvement in tobacco abstinence rates $[7,8]$. In spite of the strong evidence, it was observed in the second Global Adult Tobacco Survey 
(GATS-2) India, only $54.5 \%$ smokers were asked regarding their tobacco use status and $48.8 \%$ were advised to quit tobacco by a Health Care Professional (HCP) [9]. There is an urgent need to provide accessible and universally available tobacco cessation services for Indian population.

Dental professionals are role models and leaders who can affect the attitude of people in a community. Dentists are usually the first person to become aware of an individual's tobacco habit during the course of routine dental check-up. Dental clinic is an excellent venue for providing $\mathrm{TCl}$ to the visiting patients. Dentists can show visible evidence of the ill effects of tobacco on the oral cavity to their patients, which can motivate them to quit tobacco. Smoking cessation program run by the dentists in USA and UK had achieved quit rates of $10-20 \%[6,7]$. In spite of these facts, most of the dentists don't provide $\mathrm{TCl}$ services to their patients. Even in developed countries like USA and Canada, half of the dentists don't advise their patient to quit tobacco $[2,10]$. There are several reasons reported for this finding such as lack of time, reimbursement or training and resistance by patient [10].

India has 274154 registered dentists [11] and a dentist population ratio of $1: 10,571$ [12]. This large health care workforce can be trained and utilized to provide $\mathrm{TCl}$ to individual patients and community. Most of the dentists in India are involved in private practice of their own or as an employee. Very few dentists are working in government or private dental colleges. Therefore, if these private dental practitioners are able to provide effective $\mathrm{TCl}$ to their patients it can have an enormous public health impact. Efforts are being made at government and dental associations' level to increase the role of dental professionals in the fight against the tobacco epidemic in our country $[13,14,15]$. As per our knowledge only three studies $[16,17,18]$ have been conducted to assess the tobacco cessation efforts of private dental practitioners in India and no study is reported from Delhi which is capital of India. Therefore, a cross-sectional study was planned with the following objectives:

1. To assess the level of TCl provided by private dental practitioners in Delhi state.

2. To find out the barriers incurred in providing these interventions.

\section{Methods}

\section{Study sample}

The sampling frame for this study was all the dentists working in a private dental clinic in Delhi state. As per available records from Dental Council of India, there are 14366 registered dentists in Delhi [11]. List of dentists with their phone number or email ID was available from local IDA branch. Sample size for this survey was calculated using Epinfo software.
Required sample size was 316 (at 95\% confidence level and 5\% error margin), if we considered $70 \%$ of the dentists in Delhi are practicing $\mathrm{TCl}$ in their clinics. We contacted 330 dentists for participating in this study but only 297 dentists agreed for the same. Participating dentists were recruited using multiple methods e.g. personal visit, telephonically, by visiting conferences or continuing dental education programs organized by state dental associations, and through email. Every effort was made to give equal representation to both the genders as well as dentists practicing in urban or rural areas.

\section{Eligibility criteria}

Dentist practicing in a dental clinic in Delhi and willing to participate in the study.

\section{Ethical clearance}

An approval was obtained from institutional ethical committee before commencement of data collection (letter no. PDM/IEC/01/2019).

\section{Assessment tool}

A structured, self -administered questionnaire was prepared to record necessary information. The questionnaire was divided into five domains, starting with recording baseline information of the participating dentists, assessing their attitude towards $\mathrm{TCl}$, practice of $5 \mathrm{As}$ (Ask-Advice-Assess-Assist-Arrange) approach in their clinic, different strategies utilized to motivate their patients to quit tobacco and finally, 
self-reported roadblocks/barriers in providing these $\mathrm{TCl}$.

The face and content validity of the questionnaire was evaluated by sending it to five experts working in the field of tobacco cessation. These experts were asked to rate each question in order to assess its suitability for this study. Based on the feedback received from the experts necessary changes were made in the questionnaire. This questionnaire was then pilot tested on 20 private dental practitioners and their responses and suggestions were recorded. After these steps, the questionnaire was finalized for the main survey. Reliability of the questionnaire was assessed using Cronbach alpha test (alpha $=0.8$ ) by repeating it to ten previous study participants.

\section{Data collection}

The data were collected by single investigator (RP). Randomly selected dentists were recruited using multiple methods by the investigator e.g. telephonically, by visiting conferences or continuing dental education programs organized by state dental associations, and through email. The dentists were explained the study objectives and were asked to provide signed informed consent for participation in the study. In order to achieve a higher response rate, and wherever possible, the investigator personally visited the clinic of the participating dentists on a mutually consented time and date. The filled form were collected on the same day (preferably) or within 2 days of submission. Those dentists who agreed to fill an online form were sent a prepared Google form of the questionnaire. After receiving the filled form, the investigator checked the form to make sure all the questions are answered by the participating dentist(s). Data collection was completed within two months (June and July 2019).

\section{Statistical analysis}

The data was analyzed using Statistical Package for the Social Sciences Version 21.0 (IBM Corp., Armonk, NY, USA). Frequency distribution tables were prepared to present overall and subgroups data. Chisquare test was used to analyze the statistical differences between dichotomous independent variables such as number of years of practice, age and gender of the participating dentist with regards to responses to various sections of questionnaire (dependent variables). Probability value $(P)<0.05$ was considered as statistically significant.

\section{Results}

Baseline characteristics of the study population

We contacted 330 dentists to participate in this study, of which, 297 (155 males and 142 females) responded and gave their consent. Therefore, the response rate was $90 \%$. Baseline characteristics of study participants showed that slightly more than half (51.2\%) of the participating dentists were in age bracket of 35 years or above, and were into private practice from last 8 years or more $(\mathrm{N}=153$,
$51.5 \%)$. Around two-thirds of them ( $N=204,68.7 \%$ ) were graduate and only few had done post-graduation $(n=93,31.3 \%)$. As the numbers of dentists with graduate degree were far more than those with post-graduation, it was decided that no further comparison for outcome variables will be done between these two groups (table 1).

Table 1. Baseline characteristics of participating dentists.

\begin{tabular}{llc}
\hline Study participants & \multicolumn{2}{c}{ Total } \\
& N & \% \\
\hline $\begin{array}{l}\text { Total } \\
\text { Gender }\end{array}$ & 297 & 100 \\
$\begin{array}{l}\text { Men } \\
\text { women }\end{array}$ & 155 & 52.2 \\
Age & 142 & 47.8 \\
\hline$<=35$ years & 145 & 48.8 \\
$\begin{array}{l}\text { 36 years and above } \\
\text { Qualification }\end{array}$ & 152 & 51.2 \\
$\begin{array}{l}\text { Graduate } \\
\text { Post-graduate }\end{array}$ & 204 & 68.7 \\
$\begin{array}{l}\text { Years of practice } \\
\text { <= 8 years }\end{array}$ & 93 & 31.3 \\
9 years and above & 144 & 48.5 \\
\hline
\end{tabular}

Attitude of participating dentists towards tobacco cessation

Most of the participating dentists were aware of the fact that $\mathrm{TCl}$ can be provided in a dental clinic ( $N=265,89.2 \%$ ) and $87.5 \%$ thought $\mathrm{TCl}$ in dental clinic can be effective. Thirty six percent of the participating dentists $(\mathrm{N}=107)$ felt their patients expect them to provide $\mathrm{TCl}$ but only 51 (17.2\%) had undergone any formal training to learn these services or interventions. Majority of dentists were educating their patients regarding ill effects of tobacco on general and oral health $(n=293,98.7 \%)$.

Bivariate analysis using chi-square test showed that a significantly 
Table 2. Participating dentists' responses to questions related to providing tobacco cessation services in dental office.

\begin{tabular}{|c|c|c|c|c|c|c|c|}
\hline \multirow[t]{3}{*}{ Question } & \multirow{3}{*}{$\begin{array}{l}\text { Overall } \\
\mathrm{N}(\%)\end{array}$} & \multicolumn{2}{|c|}{ Gender } & \multirow{2}{*}{\multicolumn{2}{|c|}{$\begin{array}{l}\text { Years of practice } \\
\langle=8 \mathrm{yrs}>8 \mathrm{yrs}\end{array}$}} & \multicolumn{2}{|c|}{ Age of dentist } \\
\hline & & \multirow{2}{*}{$\begin{array}{l}\text { Male } \\
\mathrm{N}=155\end{array}$} & \multirow{2}{*}{$\begin{array}{l}\text { Female } \\
n=142\end{array}$} & & & \multicolumn{2}{|c|}{$<=35 \mathrm{yrs}>35 \mathrm{yrs}$} \\
\hline & & & & \multicolumn{2}{|c|}{$\begin{array}{l}<=8 \text { yrs }>8 y r s \\
N=144 \quad n=153\end{array}$} & $\mathrm{~N}=145$ & $n=152$ \\
\hline \multicolumn{8}{|l|}{$\begin{array}{l}\text { Are you aware of } \mathrm{TCl} \text { that can be } \\
\text { given to your patients? }\end{array}$} \\
\hline Yes & $265(89.2)$ & $133(85.8)$ & $132(93)^{*}$ & 133(92.4) & $132(86.3)$ & $135(93.1)$ & $130(85.5)^{*}$ \\
\hline No & $32(10.8)$ & $22(14.2)$ & 10(7) & $11(7.6)$ & $21(13.7)$ & 10(6.9) & $22(14.5)$ \\
\hline \multicolumn{8}{|l|}{$\begin{array}{l}\text { Have you undergone any training } \\
\text { for learning how to provide } \mathrm{TCl} \text { ? }\end{array}$} \\
\hline Yes & $51(17.2)$ & $28(18.1)$ & $23(16.2)$ & $28(19.4)$ & $23(15)$ & 28(19.3) & $23(15.1)$ \\
\hline No & $246(82.8)$ & $127(81.9)$ & $119(83.8)$ & $116(80.6)$ & $130(85)$ & $117(80.7)$ & $129(84.9)$ \\
\hline \multicolumn{8}{|l|}{$\begin{array}{l}\text { Do you explain the impact of } \\
\text { consuming tobacco on general and } \\
\text { oral health to your patients? }\end{array}$} \\
\hline Yes & 293(98.7) & $155(100)$ & $138(97.2)$ & $140(97.2)$ & $153(100)$ & $141(97.2)$ & $152(100)$ \\
\hline No & $4(1.3)$ & 0 & $4(2.8)$ & $4(2.8)$ & 0 & $4(2.8)$ & 0 \\
\hline \multicolumn{8}{|l|}{$\begin{array}{l}\text { Do you believe your patients } \\
\text { expect you to provide tobacco } \\
\text { cessation services? }\end{array}$} \\
\hline Yes & $107(36)$ & $48(31)$ & $59(41.5) *$ & $60(41.7)$ & 47(30.7)* & $63(43.4)$ & $44(28.9) *$ \\
\hline No & $190(64)$ & $107(69)$ & $83(58.5)$ & $84(58.3)$ & $106(69.3)$ & $82(56.6)$ & $108(71.1)$ \\
\hline \multicolumn{8}{|l|}{$\begin{array}{l}\text { Do you think tobacco cessation } \\
\text { interventions in dental office } \\
\text { setting can be effective? }\end{array}$} \\
\hline Yes & $260(87.5)$ & $129(83.2)$ & 131(92.3)* & $128(88.9)$ & $132(86.3)$ & 130(89.7) & $130(85.5)$ \\
\hline $\begin{array}{l}\text { Yes } \\
\text { No }\end{array}$ & 37 (12.5) & $26(16.8)$ & $11(7.7)$ & $16(11.1)$ & $21(13.7)$ & $15(10.3)$ & $22(14.5)$ \\
\hline \multicolumn{8}{|l|}{$\begin{array}{l}\text { Do you think undergoing training } \\
\text { in providing } \mathrm{TCl} \text { can help you in this } \\
\text { regard? }\end{array}$} \\
\hline Yes & $249(83.8)$ & $125(80.6)$ & $124(87.3)$ & $122(84.7)$ & $127(83)$ & $124(85.5)$ & $125(82.2)$ \\
\hline No & $48(16.2)$ & $30(19.4)$ & $18(12.7)$ & $22(15.3)$ & $26(17)$ & $21(14.5)$ & $27(17.8)$ \\
\hline
\end{tabular}

*statistically significant difference $p<0.05$, chi square test

higher awareness towards providing $\mathrm{TCl}$ in dental office was seen in dentists in older age group (>35 years) and among females. Significantly more dentists in older age group, those with more years of practice (>9 years) and females practitioners believed that their patients expect them to provide $\mathrm{TCl}$ in their clinic $(p<0.05)$. On the question of effectiveness of $\mathrm{TCl}$ in dental office, significantly more female dentists felt that such interventions are an effective tobacco control measure when compared to male dentists $(p<0.05)$ (table2).

\section{Practicing 5As approach}

Two-thirds ( $n=196,66 \%)$ of the participating dentists were asking most of their patients (more than $75 \%)$ about their tobacco use status; rest $34 \%(\mathrm{~N}=101)$ were asking from less than $75 \%$ of their total patients. Almost all of the participating dentists $(n=290,98.6 \%)$ were advising their patients (who were consuming tobacco) to quit the habit and more than $3 / 4^{\text {th }}$ ( $n=226,76.1 \%$ ) were assessing their patients' intention to quit as well as assisting them in quitting tobacco $(n=235,79.1 \%)$. Less than one-third of the participating dentists were helping their patients in setting a quit tobacco date $(n=88$, 29.6\%) and even lesser number were arranging for a follow-up appointment after the quit date $(n=$ $45,15.2 \%)$. 
Table 3. Responses of the participating dentists to questions related to 5 As approach of tobacco cessation.

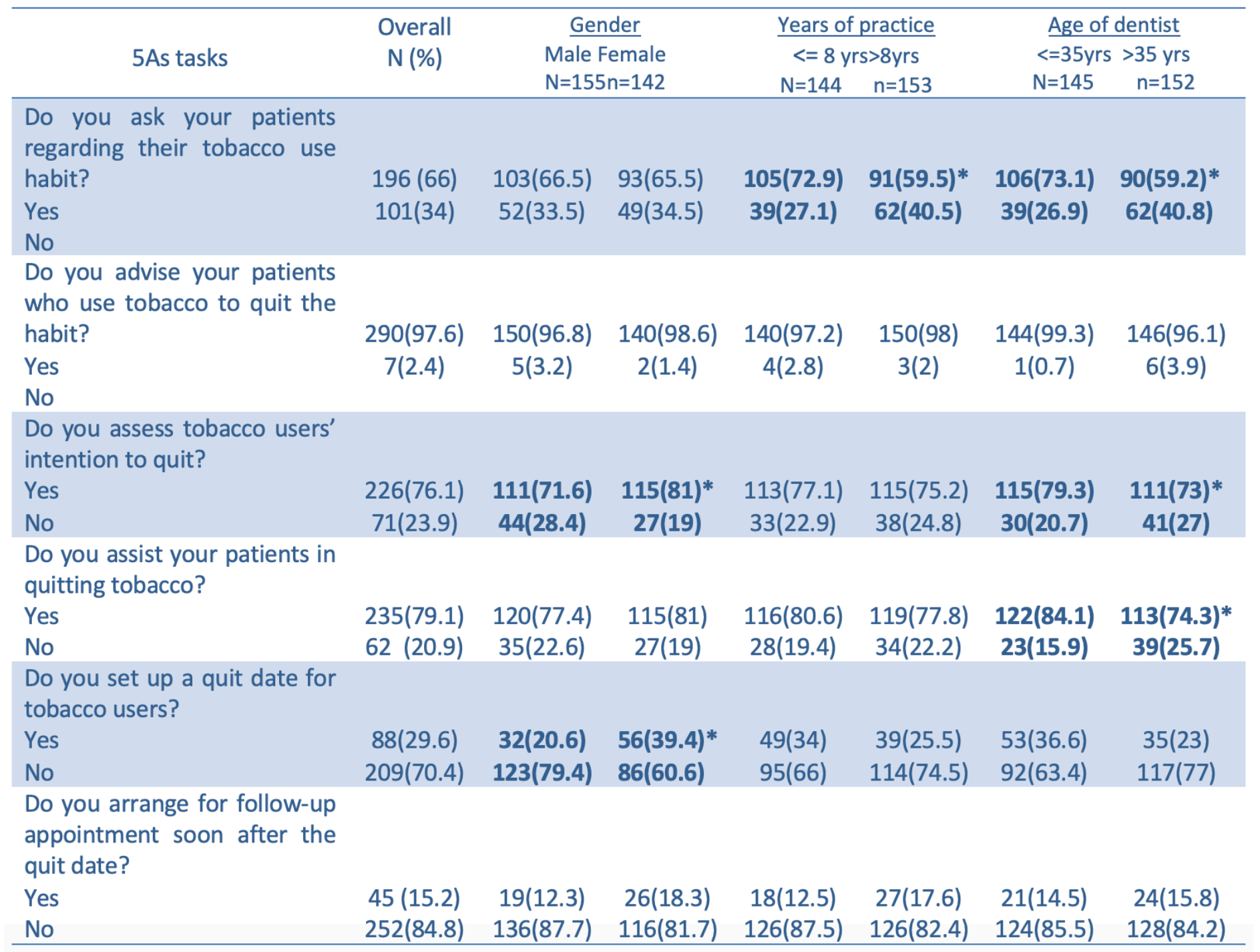

*statistically significant difference $p<0.05$, chi square test.

Female dentists' response was significantly more positive compared to the males for awareness of $\mathrm{TCl}$ provided in dental office, assessing their patient's intention to quit tobacco and arranging for follow up after quit date $(p<0.05)$. Significantly more dentists in the older age group and those who had more than eight years of practice were asking most of their patients (>75\%) regarding their tobacco use addiction. Dentist of older group (>36 years) and female dentists were assessing their patients' intention to quit tobacco in significantly higher frequency when compared to dentists of younger age ( $<35$ years) and males respectively $(p<0.05)$. There was no difference in any of these dichotomous groups about arranging follow up appointment after quit date (table 3).

Strategies for helping patients to quit tobacco
Prescribing Nicotine Replacement therapy (NRT) was the most common strategy of the participating dentists in helping their patients achieve tobacco abstinence ( $n=153,51.5 \%)$. Providing self-help educational material $(n=122$, $41.1 \%$ ) was second most common strategy followed by referring the patient to a tobacco cessation centre $(n=72,24.2 \%)$. Very few dentists were prescribing drugs such as Bupropion or Varnecline $(n=19)$ or providing tobacco quit line number 
Table 4. Strategies utilized by the participating dentists for helping their patients to quit tobacco.

\begin{tabular}{|c|c|c|c|c|c|c|c|}
\hline \multirow{2}{*}{ Strategies } & \multirow[t]{2}{*}{$\begin{array}{l}\text { Overall } \\
\mathrm{N}(\%)\end{array}$} & \multirow{2}{*}{\multicolumn{2}{|c|}{$\begin{array}{c}\quad \begin{array}{c}\text { Gender } \\
\text { Male Female } \\
\mathrm{N}=155 \mathrm{n}=142\end{array}\end{array}$}} & \multicolumn{2}{|c|}{$\frac{\text { Years of practice }}{<=8 y r s>8 y r s}$} & \multicolumn{2}{|c|}{$\begin{array}{l}\frac{\text { Age of dentist }}{<=35 \mathrm{yrs}>35 \mathrm{yrs}} \\
<=0\end{array}$} \\
\hline & & & & $\mathrm{N}=144$ & $n=153$ & $\mathrm{~N}=145$ & $n=152$ \\
\hline \multicolumn{8}{|l|}{$\begin{array}{l}\text { Providing educational material } \\
\text { to quit to bacco }\end{array}$} \\
\hline Yes & $122(41.1)$ & $57(36.8)$ & $65(45.8)$ & $60(41.7)$ & $62(40.5)$ & $67(46.2)$ & $55(36.2)^{*}$ \\
\hline No & $175(58.9)$ & $98(63.2)$ & $77(54.2)$ & $84(58.3)$ & $91(59.5)$ & $78(53.8)$ & $97(63.8)$ \\
\hline \multicolumn{8}{|l|}{ Prescribing NRT } \\
\hline Yes & $153(51.5)$ & $83(53.5)$ & $70(49.3)$ & $71(49.3)$ & $82(53.6)$ & $79(54.5)$ & $74(48.7)$ \\
\hline No & $144(48.5)$ & $72(46.5)$ & $72(50.7)$ & 73(50.7) & $71(46.4)$ & $66(45.5)$ & $78(51.3)$ \\
\hline $\begin{array}{l}\text { Prescribing drugs such as } \\
\text { Bupropion, Varnecline }\end{array}$ & & & & & & & \\
\hline Yes & 19(6.4) & $11(7.1)$ & $08(5.6)$ & $09(6.3)$ & $10(6.5)$ & $12(8.3)$ & $07(4.6)$ \\
\hline No & 278(93.6) & 144(92.9) & 134(94.4) & 135(93.8) & 143(93.5) & 133(91.7) & 45(95.4) \\
\hline \multicolumn{8}{|l|}{$\begin{array}{l}\text { Refer to a tobacco cessation } \\
\text { centre }\end{array}$} \\
\hline Yes & $72(24.2)$ & $36(23.2)$ & $36(25.4)$ & 33(22.9) & $39(25.5)$ & $36(24.8)$ & $36(23.7)$ \\
\hline No & $225(75.8)$ & $119(76.8)$ & $106(74.6)$ & 111(77.1) & $114(74.5)$ & $109(75.2)$ & 16(76.3) \\
\hline \multicolumn{8}{|l|}{$\begin{array}{l}\text { Provide them a tobacco quit } \\
\text { line number }\end{array}$} \\
\hline Yes & $14(4.7)$ & $7(4.5)$ & $7(4.9)$ & $7(4.9)$ & $7(4.9)$ & $8(5.5)$ & $6(3.9)$ \\
\hline No & 283(95.3) & $148(95.5)$ & 135(95.1) & $137(95.1)$ & $146(95.4)$ & $137(94.5)$ & 146(96.1) \\
\hline
\end{tabular}

*statistically significant difference $p<0.05$, chi square test

to their patients. Younger dentists reported to have provided educational materials to their patients in significantly higher frequency than older dentists (table 4). There was no significant difference in gender, age and years of practice groups regarding implementation of any other tobacco cessation strategies.

Self-reported barrier to providing $\mathrm{TCl}$ to a dental patient

Resistance by patient to receive $\mathrm{TCl}$ was the biggest barrier reported by the participating dentists $(n=185)$. Female dentists and those who had practiced dentistry for more than eight years reported this as a barrier significantly more than compared to male dentists and dentists with less than eight years of practice respectively. Lack of proper training in providing tobacco cessation and amount of time consumed were the other common barriers reported by the participating dentists. Significantly more dentists of older age and more years of practice felt lack of training as a barrier as compared to their comparative groups. Lack of time to provide $\mathrm{TCl}$ to their patients was significantly a more important barrier for the male dentists and dentists with less than eight years of practice. Less than fifty dentists perceived lack of reimbursement, non-familiarity with the available referral options and fear of losing patients as a barrier to $\mathrm{TCl}$ in dental clinic. No significant difference was observed between the different groups for these three barriers (table 5).

\section{Discussion}

The purpose of the present study was to evaluate the knowledge, attitude and practices of private dental practitioners of Delhi in implementing $\mathrm{TCl}$ in their dental office. Self-reported barriers encountered during these interventions were also recorded. The results of the study show most of the participating dentists believed in the effectiveness of $\mathrm{TCl}$ in dental office and many of them were implementing four (Ask-Advice-Assess-Assist) out of five tasks (except "Arrange") of 5 As approach recommended for tobacco cessation. The major lacunae (identified through this study) 
Table 5. Barriers perceived by participating dentists in providing $\mathrm{TCl}$ to their patients.

\begin{tabular}{|c|c|c|c|c|c|c|c|}
\hline \multirow[t]{2}{*}{ Barriers } & \multirow[t]{2}{*}{$\begin{array}{l}\text { Overall } \\
\mathrm{N}(\%)\end{array}$} & \multirow{2}{*}{\multicolumn{2}{|c|}{$\begin{array}{c}\underline{\text { Gender }} \\
\text { Male Female } \\
\mathrm{N}=155 \mathrm{n}=142\end{array}$}} & \multicolumn{2}{|c|}{$\frac{\text { Years of practice }}{<=8 \text { yrs }>8 y r s}$} & \multicolumn{2}{|c|}{$\frac{\text { Age of dentist }}{<=35 \mathrm{yrs}>35 \mathrm{yrs}}$} \\
\hline & & & & $\mathrm{N}=144$ & $n=153$ & $\mathrm{~N}=145$ & $n=152$ \\
\hline \multicolumn{8}{|c|}{ Lack of time } \\
\hline Yes & $124(41.8)$ & $72(46.5)$ & $52(36.6)^{*}$ & $68(47.2)$ & $56(36.6)^{*}$ & $61(42.1)$ & $63(41.4)$ \\
\hline No & $173(58.2)$ & $83(53.5)$ & $90(63.4)$ & $76(52.8)$ & $97(63.4)$ & $84(57.9)$ & $89(58.6)$ \\
\hline \multicolumn{8}{|c|}{ Lack of training } \\
\hline Yes & $146(49.2)$ & $72(46.5)$ & $74(52.1)$ & $63(43.8)$ & $83(54.2) *$ & $64(44.1)$ & $82(53.9) *$ \\
\hline No & $151(50.8)$ & $83(53.5)$ & $68(47.9)$ & $81(56.3)$ & $70(45.8)$ & 81(55.9) & $70(46.1)$ \\
\hline \multicolumn{8}{|c|}{ Resistance by patients } \\
\hline Yes & $185(62.3)$ & $89(52.4)$ & $96(67.6)^{*}$ & $76(52.8)$ & $109(71.2)^{* *}$ & $86(51.3)$ & $99(65.1)$ \\
\hline No & $112(32.7)$ & $66(42.6)$ & $46(32.4)$ & $68(47.2)$ & $44(28.8)$ & $59(40.7)$ & $53(34.9)$ \\
\hline \multicolumn{8}{|c|}{ Fear of losing patients } \\
\hline Yes & $48(16.2)$ & $28(18.1)$ & $20(14.1)$ & $25(17.4)$ & 23(15) & $21(14.5)$ & $27(17.8)$ \\
\hline No & $249(83.8)$ & $127(81.9)$ & $122(85.9)$ & $119(82.6)$ & $130(85)$ & $124(85.5)$ & $125(82.2)$ \\
\hline \multicolumn{8}{|c|}{$\begin{array}{l}\text { Not familiar with referral } \\
\text { options }\end{array}$} \\
\hline Yes & $49(16.5)$ & $25(16.1)$ & $24(16.9)$ & $22(15.3)$ & $27(17.6)$ & $21(14.5)$ & $28(18.4)$ \\
\hline No & $248(83.5)$ & 130(83.9) & $118(83.1)$ & $122(84.7)$ & $126(82.4)$ & $124(85.5)$ & $124(81.6)$ \\
\hline \multicolumn{8}{|c|}{ Lack of reimbursement } \\
\hline Yes & $42(14.1)$ & $28(18.1)$ & 14(9.9) & 16(11.1) & $26(17)$ & $16(11)$ & $26(17.1)$ \\
\hline No & 255(85.9) & $127(83.9)$ & 128(88.9) & $128(88.9)$ & $127(83)$ & $129(89)$ & $126(82.9)$ \\
\hline
\end{tabular}

*statistically significant difference $p<0.05, * * p<0.001$, chi square test

hindering the proper implementation of $\mathrm{TCl}$ by the participating dentists were lack of formal training, most of the dentists didn't think that patients expect them to provide $\mathrm{TCl}$, and there was lack of proper follow- up mechanism of tobacco users in the dental office.

Tobacco treatment guidelines developed by Government of India [4] had suggested strategies for tobacco cessation in the form of $5 \mathrm{As}$ (if person is willing to quit tobacco) or 5Rs approach (if person is not willing to quit tobacco) [7]. These guidelines are research-based and accepted globally [19]. A typical TCI involves counseling session of approximately 5-8 minutes to each tobacco user using $5 \mathrm{As}$ approach. If this is not possible (due to lack of time) a brief intervention session (approx. 2-3 minutes) that requires Health Care Professionals (HCP) to Ask every patient regarding their tobacco status, Advise them on quitting tobacco and Assess their willingness to quit $(3 A s)[2,20]$. In our study, only $66 \%$ participating dentists were asking the majority of (more than $75 \%$ ) their patients about tobacco consumption status. These numbers are quiet similar to those reported among dentists of Saudi Arabia and Kuwait [21], United Kingdom [22], Iran [23] and Netherlands [24] but higher than that reported in Canada [10] and Udaipur, India [25] and lesser than that reported in Pakistan [26], Modinagar, India [16], Nigeria [27], Yemen [28] and United states of
America [29]. Asking about tobacco consumption status is the foremost step a HCP must perform towards identifying patients who are addicted to tobacco. Hence there is need to improve the awareness of all HCP to ask each and every patient regarding their tobacco history. In our study, most (97.6\%) of the participating dentists were advising tobacco users to quit. This percentage was much higher than that reported by similar studies around the world $[10,16,21,23,25,26,27,29]$. It is an encouraging finding since research had shown even a brief advice by HCP could motivate patient to quit or at least reduce tobacco consumption [30]. Around $3 / 4^{\text {th }}$ of the study participants $(76.1 \%)$ were 
assessing their patients' intention to quit tobacco. These figures are much higher than that reported by similar studies $[10,23,25,27]$. As per GATS-2 India less than $15 \%$ of tobacco users were planning to quit in next one year and even less than $10 \%$ in next one month [9]. These figures are suggestive of failure on part of health care services to motivate tobacco users to quit the habit. Obtaining information on patient' intention to quit helps dental professionals to evaluate tobacco user motivation to quit tobacco. Along with setting a quit date, intention to quit has been found to be associated with higher tobacco abstinence rates [20].

Assisting the tobacco users in quitting the habit requires time and commitment from health care professionals. In present study, more than $3 / 4^{\text {th }}(79.1 \%, n=235)$ of the participating dentists had reported to assist their patients in achieving tobacco abstinence. However, when specifically asked about the strategies for assistance, less than $30 \%$ of the participating dentists were helping their patients to set a quit date and even fewer (15.2\%) stated that they were arranging a follow-up appointment for tobacco users. These numbers are much less than that is reported by studies done in Canada [10], US [29] and Nigeria [27] but higher than studies done in Pakistan [26], Iran [23] and Udaipur, India [31]. These observations reflect a lack of long term commitment of participating dentists to make sure their patients are free of tobacco addiction. It is a widely known fact that tobacco users require multiple attempts before they finally quit [32]. Therefore, if a health care professional is not providing an option of future follow up it will ultimately lead to poor abstinence rate among its patients. Follow-up appointments are also extremely important for dentists to reinforce their health education message and for patients for sharing problems they are facing during the process of tobacco abstinence. Patients must be reminded repeatedly regarding immediate and long-term benefits of quitting tobacco [33].

Most common strategies utilized by participating dentists to help their patients quit tobacco were prescribing NRT, providing self-education material and referring to a tobacco cessation centre. Frequency of self-reported prescription of NRT to their patients was much higher in our study sample compared to similar studies $[10,16,22,26,29]$. Prescribing NRT is an effective method of replacing nicotine obtained from direct tobacco products and has shown to increase the chances of tobacco abstinence rate up to $50-70 \%$ [34].

In our study, we tried to find out the barriers impeding implementation of $\mathrm{TCl}$ by the participating dentists. "Resistance by patients" was the most common barrier reported by the dentists. Studies done among dentists of European Union [35] and Canada [10] had found this factor as one of the main barrier. "Lack of adequate training" in providing $\mathrm{TCl}$ was another important barrier reported. Dentists without proper knowledge and training will lack confidence in conducting $\mathrm{TCl}$ in their office and hence would not be able to motivate their patient to quit tobacco. Similar results were observed by studies conducted in different parts of the world $[10,16,27]$. "Lack of time" to provide $\mathrm{TCl}$ was the third most common barrier reported by the dentists in our study. Many studies had reported this as one of the most common barrier $[10,18,21,22,25,27]$. Dental treatment is inherently laborious and requires more time for a single patient or procedure when compared to a general physician. The dentists must be educated and motivated towards the rewards and responsibilities of providing $\mathrm{TCl}$. In the present study, Lack of monetary benefit from $\mathrm{TCl}$ was considered as a barrier by only 42 (14.1\%) dentists. This figure is quiet lower when compared to other studies around the world [10,22,27] and India $[18,19]$ except for one Indian study [16]. $\mathrm{TCl}$ in dental office is usually not a reimbursable service. Although efforts should be directed to include it as a chargeable service but more importantly dentists must be educated that tobacco cessation activities can help them build a reputation with their patients and neighborhood community.

Bivariate comparative analysis of the study participants shows younger dentists ( $<35$ years of age) had better awareness and self- 
belief regarding provision of $\mathrm{TCl}$ in their clinic. Dentist of younger age group performed significantly better in implementing Ask, Advice and Assist tasks of 5 As approach to their patients. They were providing self-help education materials in higher frequency as compared to dentists above 35 years of age. Finally, the younger dentists didn't perceive lack of training as a barrier in providing $\mathrm{TCl}$ when compared to older dentists. Possible explanation for such observations could be better awareness of younger generation of dentists regarding importance of providing $\mathrm{TCl}$ to their patients. It could be due to changes in dental school's curriculum with compulsory lectures as well as hands on training for dental students on tobacco cessation [36]. Establishment of tobacco cessation centre is now mandatory for all dental colleges in India [13]. This initiative will increase practical knowledge and confidence of graduates in providing $\mathrm{TCl}$ to their patients once they come out of dental college and open there clinic. There has been better availability of training in form of continuing education and workshops on tobacco cessation which helps private practitioners to update their knowledge on tobacco cessation.

\section{Limitations and strengths}

The present study is not without limitations and therefore its results should be interpreted keeping them in mind. This study is limited to private dentists practicing in Delhi state. Therefore, these results are not representative of dental professionals of the whole country. Second, the findings of the study are based on self-reported answers where individuals might report good knowledge of a particular topic without undergoing assessment on its practical implementation part. For example, most dentists are aware and understand the importance of tobacco cessation but whether they are actually implementing it in their dental office cannot be assessed with a questionnaire study. Such self-reporting studies are also prone to recall bias. Third, is the issue of selection bias in the study sample, as dentists interested and motivated towards $\mathrm{TCl}$ may get enrolled for this study. We feel chances of selection bias is less in our sample as refusal rate (not to participate in the study) is just ten percent and every attempt was made to recruit dentists regardless of their past experience in providing $\mathrm{TCl}$. Fourth, as this study is cross sectional in design therefore it's not suitable to draw any causal relationships. Finally, we didn't assess participating dentists own habit of tobacco use. It has been reported that dentists who smoke tobacco are less keen on engaging their patients for $\mathrm{TCl}[21,28]$.

\section{Conclusions}

The results of our study present an overview of the current scenario of tobacco cessation efforts made by private dental practitioners of Delhi and barriers experienced by them. Efforts should be made to eliminate these barriers and increase the practical knowledge of dentists on providing $\mathrm{TCl}$ to their patients. Efficient and skill-based training provided through changes in dental curriculum, conducting workshops and online courses could help in increasing tobacco abstinence among Indian population.

\section{Acknowledgments}

This study was selected by Indian Council of Medical Research for funding under their studentship scheme (ICMR-STS 2019).

Conceptualization: AM. Data curation: AM, GK, RP, SK. Formal analysis: AM, SK. Funding acquisition: RP, SK. Methodology: AM, GK, SK. Project administration: AM, GK, SK, RP. Visualization: AM, GK, RP, SK. Writing - original draft: AM, GK. Writing - review \& editing: AM, GK, RP, SK. The authors have no conflicts of interest to declare for this study.

\section{References}

1. Global, regional, and national disability-adjusted life-years (DALYs) for 359 diseases and injuries and healthy life expectancy (HALE) for 195 countries and territories, 1990-2017: a systematic analysis for the Global Burden of Disease Study 2017.

GBD 2017 DALYs and HALE Collaborators.Lancet. 2018 Nov 10;392(10159):18591922. doi: 10.1016/S0140- 
6736(18)32335-

3.PMID: 30415748

2. Dentistry's role in tobacco control.

Tomar SL.J Am Dent Assoc. 2001 Nov;132 Suppl:30S35S. doi: 10.14219/jada.archive.2001.0386.PMID: 118 03650

3. A quasi-experimental intervention to assess the effectiveness of a physician-delivered

tobacco cessation intervention in India: A detailed study protocol.

Panda R, Health P, Gaurav $K$, Health $P$, Pati $S$, Mathur MR. SAGE Open Med. 2017;5:1-8.

doi: $10.1177 / 20503121176$

97173. PMID: 28540045

4. MInistry of Health and Family Welfare Government of India. Tobacco Dependence Treatment Guidelines.; 2011.

5. Physician advice for smoking cessation.

Stead LF, Buitrago D, Preciado N, Sanchez G, Hartmann-Boyce J, Lancaster T.Cochrane Database Syst Rev. 2013 May 31;2013(5):CD000165. doi: 10.1002/14651858.CD0001 65.pub4.PMID: 23728631

6. Effectiveness of tobacco counseling in the dental office.
Warnakulasuriya S.J Dent Educ. 2002 Sep;66(9):107987.PMID: 12374269

7. Tobacco cessation in dental settings: research findings and future directions.

Gordon JS, Lichtenstein $\mathrm{E}$, Severson $\mathrm{HH}$, Andrews JA.Drug Alcohol Rev. 2006 Jan;25(1):27-37. doi: 10.1080/09595230500459 495.PMID: 16492575

8. Interventions for tobacco cessation in the dental setting.

Carr AB, Ebbert J.Version 2. Cochrane Database Syst Rev. 2012 Jun 13;2012(6):CD005084. doi: 10.1002/14651858.CD0050 84.pub3.PMID: 22696348

9. Ministry of Health and family welfare government of India. Global Adult Tobacco Survey (GATS)-2 India.

https://www.mohfw.gov.in /sites/default/files/GATS-2 FactSheet.pdf

10. Tobacco use cessation services provided by dentists and dental hygienists in Manitoba: part 1. Influence of practitioner demographics and psychosocial factors.

Brothwell DJ, Gelskey SC.J Can Dent Assoc. 2008 Dec;74(10):905.PMID: 191 26359

11. Dental Council of India. Total registered dentists. Accessed January 14, 2019. http://www.dciindia.org.in /DentistRegistered.aspx

12. Dental manpower planning in India: current scenario and future projections for the year 2020.

Vundavalli S.Int Dent J. 2014 Apr;64(2):62-7. doi: 10.1111/idj.12063. Epub 2013 Nov

4.PMID: 24180215

13. Government of India. Establishment of Tobacco Cessation Centers in Dental Institutes: An Integrated Apporach in IndiaOperational Guidelines 2018.; 2018.

14. Role of dental institutions in tobacco cessation in India: current status and future prospects.

Mohanty VR, Rajesh GR, Aruna DS.Asian Pac J Cancer Prev. 2013;14(4):267380.

doi: 10.7314/арjср.2013.14.4.2 673.PMID: 23725194

15. World Health Organization. Effective Implementation of the WHO Framework Convention on Tobacco Control through the MPOWER Policy Package. TFI NewsI. 2009;2(2):1-8.

16. Tobacco Cessation Counselling Practices and Attitude among the Dentist and the Dental Auxiliaries of Urban and Rural Areas of Modinagar, India.

Singla A, Patthi B, Singh $K$, Jain S, Vashishtha V, Kundu H, Malhi R, Pandita V.J Clin 
Diagn Res. 2014 Sep;8(9):ZC15-8. doi: 10.7860/JCDR/2014/9250.

4799. Epub 2014 Sep 20.PMID: 25386513

17. Tobacco cessation and counseling: a dentists' perspective in Bhopal city, Madhya Pradesh.

Amit S, Bhambal A, Saxena V, Basha S, Saxena S, Vanka A.Indian J Dent Res. 2011 May-Jun;22(3):400-3. doi: 10.4103/0970-

9290.87061.PMID: 220485 79

18. Addressing tobacco control in dental practice: a survey of dentists' knowledge, attitudes and behaviours in India.

Chandrashekar J, Manjunath BC, Unnikrishnan M.Oral Health Prev Dent. 2011;9(3):243-

9.PMID: 22068180

19. Knowledge, Attitude and Practice Regarding Tobacco Cessation Among Indian Dentists.

Shaheen S, Reddy S, Doshi D, Reddy P, Kulkarni S.Oral Health Prev Dent. 2015;13(5):427-34. doi: 10.3290/j.ohpd.a33924.PM ID: 25789360

20. Factors determining intention to quit tobacco: exploring patient responses visiting public health facilities in India.

Panda R, Venkatesan S, Persai D, Trivedi M, Mathur MR.Tob Induc Dis.
2014 Jan 20;12(1):1. doi: 10.1186/1617-9625-12-

1.PMID: 24444137

21. Tobacco cessation support among dentists: A crosssectional survey in Saudi Arabia and Kuwait.

Alajmi B, Abu-Hammad O, Al-Sharrad A, Dar-Odeh N.Tob Prev Cessat. 2017 Aug 1;3:121. doi: $10.18332 / \mathrm{tpc} / 75795$. eCollection

2017.PMID: 32432195

22. Tobacco cessation activities of UK dentists in primary care: signs of improvement. Johnson NW, Lowe JC, Warnakulasuriya $\mathrm{KA} . \mathrm{Br}$ Dent J. 2006 Jan 28;200(2):85-9. doi: 10.1038/sj.bdj.4813148.P MID: 16444223

23. Attitude and practices among dentists and senior dental students in iran toward tobacco cessation as an effort to prevent oral cancer.

Razavi SM, Zolfaghari B, Doost ME, Tahani B.Asian Pac J Cancer Prev. 2015;16(1):333-8. doi: 10.7314/apjcp.2015.16.1.3 33.PMID: 25640375

24. Facilitating smoking cessation in patients who smoke: a large-scale cross-sectional comparison of fourteen groups of healthcare providers.

Meijer E, Van der Kleij RMJJ, Chavannes NH.BMC Health Serv Res. 2019 Oct
25;19(1):750. doi: 10.1186/s12913-019-4527x.PMID: 31653215

25. Attitudes, Practices and Perceived Barriers in Smoking Cessation among Dentists of Udaipur City, Rajasthan, India.

Bhat N, Jyothirmai-Reddy J, Gohil M, Khatri M, Ladha M, Sharma M.Addict Health. 2014 Winter;6(1-2):7380.PMID: 25140220

26. Farrukh $U$, Shakeel $S$. Dentists' Practice and Perceived Barriers towards Smoking Cessation and Intervention in Karachi, Pakistan. J Pharm Care Heal Syst. 2016;03(01):1-5.

27. TOBACCO CESSATION SERVICES AND RELATED CHALLENGES AMONG DENTISTS IN SOUTHWEST NIGERIA.

Dedeke AA, Popoola OA, Adebiyi AO, Asuzu MC.Ann Ib Postgrad Med. 2018 Dec;16(2):125130.PMID: 31217769

28. Tobacco Cessation Counseling: Attitudes and Practices among Yemeni Dental Professionals.

Al-Maweri SA, Al-Soneidar WA, AlMaqtari A, Hunaish A, Al-Sufyani G, Halboub E.J Cancer Educ. 2018 Oct;33(5):1088-1093. doi: 10.1007/s13187-017-12129.PMID: 28324226

29. Dentists' attitudes, behaviors, and barriers related to 
tobacco-use cessation in the dental setting.

Prakash P, Belek MG, Grimes B, Silverstein $S$, Meckstroth R, Heckman B, Weintraub JA, Gansky SA, Walsh MM.J Public Health Dent. 2013 Spring;73(2):94102. doi: $10.1111 / \mathrm{j} .1752-$ 7325.2012.00347.x. Epub 2012 Jun

26.PMID: 22731618

30. Guidance for commissioners on the cost effectiveness of smoking cessation interventions. Health Educational Authority.

Parrott S, Godfrey C, Raw $M$, West R, McNeill A.Thorax. 1998 Dec;53 Suppl 5 Pt 2(Suppl 5):S138.PMID: 10226676

31. Assessment of Knowledge, Attitude, Behaviour and Interpersonal Factors Related to the Use of Tobacco among Youth of Udaipur City, Rajasthan, India: A Cross-Sectional Study.

Multani S, Reddy JJ, Bhat N, Sharma A.Addict Health. 2012 Summer-Autumn;4(34):142-50.PMID: 24494149

32. Treating tobacco use and dependence: 2008 update U.S. Public Health Service Clinical Practice Guideline executive summary.

2008 PHS Guideline Update Panel, Liaisons, and Staff. Respir Care. 2008. PMID: 18807274

33. World Health Organisation (WHO). The role of health professionals in tobacco control. World Heal Organ. Published online 2005:138.

http://www.who.int/tobac co/resources/publications/ wntd/2005/bookletfinal_2 Oapril.pdf

34. Nicotine replacement therapy for smoking cessation.

Stead LF, Perera R, Bullen C) Mant D, HartmannBoyce J, Cahill K, Lancaster T.Cochrane Database Syst Rev. 2012 Nov 14;11:CD000146. doi: 10.1002/14651858.CD0001 46.pub4.PMID: 23152200

35. Tobacco and oral health: attitudes and opinions of European dentists; a report of the EU working group on tobacco and oral health.

Allard RH.Int Dent J. 2000 Apr;50(2):99-102. doi: 10.1002/j.1875-

595x.2000.tb00806.x.PMID : 10945189

36. Dental council of India. BDS Course Regulations.; 2007. Accessed December 30, 2019.

http://www.dciindia.gov.in /Rule_Regulation/Revised_ BDS_Course_Regulation_2 007.pdf 